Article

\title{
Breaking the cycle: Women's perceptions of the causes of violence and crime in informal settlements in Nairobi, Kenya and their strategies for response and prevention
}

\section{Samantha C. Winter ${ }^{*}$, Lena Moraa Obara ${ }^{2}$, Nathan Jason Aguilar ${ }^{1}$, and Laura Johnson ${ }^{3}$}

${ }^{1}$ School of Social Work, Columbia University

${ }^{2}$ School of Social Work, Rutgers, The State University of New Jersey

${ }^{3}$ School of Social Work, Temple University

\begin{abstract}
The purpose of this study was to identify potential causes of violence and crime in informal settlements and residents' strategies for response and prevention to these issues, as perceived by women living in Mathare informal settlement in Nairobi, Kenya. A total of 55 in-depth interviews were conducted with women living in the informal settlement in 2015-2016. A modified grounded theory approach was used to guide data collection and analysis. The most common contributor to violence and crime identified by women in Mathare informal settlement was idle youth, but leadership and government challenges, corruption and/or inadequacy of police, community barriers, tribalism, and lack of protective infrastructure also emerged as contributing factors. Despite facing many economic, environmental, and day-to-day challenges, women in Mathare identified violence and crime as predominant issues; thus, developing effective response and prevention strategies to these issues in informal settlements is paramount. Women suggest there are many strategies and initiatives to reduce and prevent violence and crime in informal settlements, but also identified barriers to implementing them. Findings suggest there is a need for trustbuilding between formal and informal organizations and institutions, systems of accountability, and long-term investment to foster sustainable and effective violence and crime response and interventions in these settlements.
\end{abstract}

Keywords: violence, crime, informal settlements, women, Kenya

*Correspondence concerning this article should be addressed to Samantha Winter, Columbia University, 1255 Amsterdam Avenue, New York, NY 10027. Email: scw2154@columbia.edu 


\section{Introduction}

There is limited research focused on the causes of violence and crime in informal settlements in the Global South, and most of the theories explaining urban inequality, poverty, violence, and crime in cities, more broadly, draw on experiences and narratives from countries in the Global North, particularly from cities in the United States (Salahub et al., 2018). A small but growing body of research, coming largely out of the Global South, links urban violence and insecurity to social, economic, and political exclusion (Berkman, 2007; Salahub et al., 2018; Ward et al., 2013; Williams \& Castellanos, 2020). This body of literature suggests that the determining factor in urban violence is not just a lack of resources or poverty, but a lack of social inclusion in urban society. Much of this research highlights patterns of social, economic, and political exclusion that create space for manifestations of violence and crime, which work to reinforce power structures and systems of exclusion in these cities (Salahub et al., 2018). Relatedly, much of this scholarship links violence and crime to specific factors that represent exclusion from urban society including income and social inequality, concentrated poverty, impunity for officials who fail to act or who act violently or immorally, lack of access to formal services and markets, and high unemployment, especially for young men (Moncada, 2013; Salahub et al., 2018). This exclusion also augments feelings of insecurity, e.g., fear of victimization, for women in these settings (Anwar et al., 2018).

In this paper, we look to women living in one of these settlements to help identify potential causes of violence and crime in informal settlements and prevention and response strategies. We start by looking, briefly, at crime causation theory and, specifically, what is known about the causes of urban violence in informal settlements and urban communities in the Global South. We also discuss the role of community residents, especially women, in helping to ensure safety and security in these settlements. We then present women's narratives of the causes of and prevention and response strategies to crime and violence in this context. Finally, we discuss the implications of the findings from this study for helping to guide strategies to reduce crime and violence in informal settlements.

\subsection{Causation of Violence and Crime}

Criminologists have developed a number of theoretical explanations of crime, most of which were developed in the Global North and have been applied minimally in subSaharan African (SSA). These theories range from micro- to macro-level explanations of crime and violence. There are individual-level explanations, which suggest that 
criminality is a result of biological traits or psychological characteristics and behaviors (Herbert, 2002). Additional explanations, e.g., social learning theory, suggest crime is learned and reinforced primarily through association with or exposure to others (Akers, 1998). Strain theory, posits that people engage in crime to reduce the strain they are experiencing. For example, people might engage in crime or violence when they experience strain in achieving their goals (e.g., status/respect, financial goals, or independence) or are presented with negative or toxic conditions, such as financial strain, harassment, abuse, neglect, victimization, negative relationships, social or economic problems, unemployment, or lack of opportunities (Agnew, 1992). Still other theories, i.e., control theories, which include general crime theory, assume that crime is an easier and more expeditious way to achieve one's goals; thus, only controls or restraints placed on people prevent them from engaging in crime. These controls can, for example, be internal, e.g., self-control; social, e.g., a desire to conform to social norms and standards; or direct, e.g., people or institutions setting rules and monitoring behavior (Gottfredson \& Hirschi, 1990; Hirschi, 1969). Labeling theories provide yet another explanation for crimesuggesting that individuals who are labelled, formally or informally, as delinquent or criminal, particularly those who occupy marginalized positions in society, e.g., young male residents of urban informal settlements, are more likely to engage in crime because they are treated as delinquent or criminal by others in society, including police and criminal justice systems. People who are labelled as delinquent or criminal, even if they are not actually engaging in criminal behavior, may internalize these perceptionsbelieving they are delinquent (Matsueda, 1992). There are also situational theories that suggest that crime and violence are more likely to happen in specific situations when the benefits of crime outweigh the costs. Routine activities perspective, for example, suggests that crime and violence are most likely to happen when motivated offenders and attractive targets come together in the absence of capable guardians (Felson, 1998).

Additionally, there are theories of crime tied to development, e.g., modernization theory, which posits that as societies become increasingly modernized, the disruptions to authority and social and communal structures cause people to feel insecurity and anomie and engage in criminal activity. Moreover, underdevelopment theory "links the rise of crime to the economic and social miseries produced by an imposed capitalist colonial and neo-colonial order and system of law" (Arthur \& Marenin, 1995, p. 201). There are also neighborhood- or collective-level crime theories, such as social disorganization theory, that have been used to help explain crime in urban communities in the Global North (see, for example, Brunton-Smith et al., 2014; Bursik, 1988; Markowitz et al., 2001; Taylor \& Covington, 1993; Villarreal \& Silva, 2006; Woldoff, 2006) and in SSA (G. Breetzke, 2010; G. D. Breetzke, 2010; Breetzke \& Horn, 2008; Lamb, 2019; Parks, 2014; Roberts \& Gordon, 2016). Generally, social disorganization theory suggests that when people live in structurally disadvantaged neighborhoods, e.g., those with high rates of poverty, 
unemployment, economic insecurity, exclusion, and racial or ethnic heterogeneity, they tend to be less trusting of others and experience a strain on community trust, cohesion, and, importantly, collective efficacy (Sampson, 2012). According to the theory, these burdens, coupled with a lack of resources, hinder one's ability to provide assistance to fellow residents in need or to come together for the common good of the neighborhood, e.g., for crime and violence prevention and response (Sampson, 2012). This results in higher levels of crime and delinquency in the neighborhood (Sampson \& Groves, 1989; Sampson et al., 2002; Shaw \& McKay, 1942).

\subsection{The Role of Oppression and Exclusion in Crime E Violence in Informal settlements}

While many of the sociological crime causation theories can provide a helpful framework for exploring distribution and causation of crime in various urban contexts, many do not account for an examination of systems of oppression that cause, contribute to, or perpetuate structural disadvantage in informal settlement communities. Literature focused on SSA cities, for example, highlights the role colonialism played in creating and perpetuating current systems of exclusion and control that target specific groups along political, economic, tribal, ethnic, and/or gender lines and in creating structural disadvantage in communities (Darkey \& Kariuki, 2013; Stewart \& Katsande, 2018; Wanjiru \& Matsubara, 2017). Research illustrates that intangible aspects of exclusion, such as normalized violence against particular social groups, may be stronger predictors of crime and violence than conditions of poverty and material deprivation (Berkman, 2007; Salahub et al., 2018). In Nairobi, Kenya, for example, policies developed during British colonial rule were used to control migration of African natives into the city and to segregate and exclude those who did migrate-effectively forcing migrants to settle in the lowlands, flood plains, valleys, wetlands, and waste dumps that are the sites of today's informal settlements (Darkey \& Kariuki, 2013; Wanjiru \& Matsubara, 2017). Postindependence, exclusion of informal settlements from formal systems and services continued and was normalized (Darkey \& Kariuki, 2013). Normalization of violence as a form of exclusion of residents of informal settlements has been evident in the threatened and actual demolition of homes; extortion and harassment of residents; lack of police presence followed by periodic and violent police raids; land conflicts and tenure struggles; corrupt government or police presence; and violent electoral protests orchestrated by politicians (Darkey \& Kariuki, 2013; Elfversson \& Höglund, 2019; Fox, 2014; Salahub et al., 2018; Stavrou, 2002; Stewart \& Katsande, 2018). In these settlements, violence is fed by failures of the state to meet its "social contract" with residents by limiting: delivery of quality, consistent, and widely-available services to residents; investment in adequate infrastructure; provision of acceptable policing and security; access to opportunities for employment or access to formal labor markets; and expansion of government-supported programs and resources in settlements (Salahub et al., 2018). 
This breach of the social contract between the government and settlements undermines trust, civic responsibility, support of, and engagement in governmental efforts to reduce crime and insecurity (Stavrou, 2002).

Research focused on young men and masculinities in informal settlements in SSA further suggest that social, political, and, especially economic exclusion, destabilizes traditional gender roles and norms in these settlements-yielding violent results (Gibbs et al., 2014; Izugbara \& Egesa, 2019; Mariano et al., 2018). Men face serious challenges to their traditional ideas of masculinity when confronted with limited opportunities for employment and civic engagement. Being locked out of formal labor markets has been considered a key pre-condition for petty crime and the formation of violent local armed actors, comprised mostly of young men (Moncada, 2013). In an effort to exercise their power in the face of these challenges, they engage in violence towards others, particularly women (Mariano et al., 2018).

\subsection{Reducing Violence and Crime in Settlements: The Role of Community and Women}

According to recommendations made in a 2002 crime victims survey carried out in Nairobi, Kenya, violence and crime prevention and response strategies "must be found with communities and through mechanisms based on local culture and the resources and capacities of the various stakeholders" (Stavrou, 2002, p. 2). These sentiments are echoed in more recent analyses exploring perspectives on lasting solutions to urban violence in Global South cities, which state that response to and prevention of urban violence must be developed locally and tailored to local realities (de Boer et al., 2018). Underlying causes of urban violence are often rooted in structural, legal, social, and political policies and practices. Approaches that do not take into consideration the structural arrangements that define social norms and who can and cannot access services, exercise their basic rights, and prosper in urban society will reinforce existing systems of exclusion and exacerbate vulnerability (de Boer \& Gottsbacher, 2019). Residents living and working in these communities have unparalleled insights into these phenomena (de Boer et al., 2018). Yet, the lack of research focused on the perspectives of residents of informal settlements may serve to reinforce the systems of exclusion that contribute to urban violence and crime and complicate or undermine response and prevention strategies.

To date, there is a dearth of evidence about effective strategies for reducing and preventing violence and crime in informal settlements and in cities in the Global South, more broadly (de Boer et al., 2018). There is also a paucity of inquiry into the barriers to implementation of existent strategies; yet, identifying potential barriers may be a critical next step. We agree with theories positing that the root causes of violence and crime in informal settlements in cities in the Global South are largely structural-rooted in 
exclusion, marginalization, and discrimination; thus, we feel it is important to recognize how these systemic issues may also create barriers to change at the community level. Research suggests, for example, that in informal settlements and poor urban neighborhoods, where residents have been consistently excluded from urban society, there are high levels of distrust in official institutions and police (Mahadevia \& Desai, 2019; Stavrou, 2002). Reporting levels to police are low in informal settlements, especially for women, because residents do not believe police can assist them or, in the worst case, they believe the police are corrupt, violent, or colluding with criminals (Stavrou, 2002). According to responses from the 2002 crime victim survey in Nairobi, for example, residents believe bribery is not only a part of the problem in the city, but also part of the solution (Izugbara \& Egesa, 2019; Stavrou, 2002)-undermining institutional efforts to reduce crime and violence in informal settlements. Thus, recommendations for violence and crime encourage people to take responsibility for their own safety while fostering a shared sense of responsibility and partnerships between government and civil society that help to rebuild trust (Stavrou, 2002).

Recent research suggests that women may be central to building social cohesion and trust as well as restoring agency and the capacity of communities to collectively address violence and crime (Brankovic, 2016; Langa et al., 2019). Yet, women are seemingly absent from much of the research focused on violence and crime prevention and reduction in informal settlements. Recent literature suggests that some men believe they are better suited to lead community development initiatives in informal settlements than women (Izugbara et al., 2014). Other literature suggests that women represent a smaller proportion of perpetrators and victims of violent crimes than men (Shaw \& Carli, 2011; Ziraba et al., 2011); thus, research focused on crime and violence in informal settlements in SSA often focuses on the experiences and voices of young men except in the domain of sexual and intimate partner violence. However, research that includes reports of violence by gender in SSA suggest women may experience higher rates of certain violent crimes than men, e.g., kidnappings, assault, rape, and attempted rape (Owusu et al., 2019) and women are also more affected by fear of violence (Doran \& Burgess, 2011; Krug et al., 2002). Women's response to this fear is often to adopt avoidance behaviors, e.g., avoiding certain places or minimizing going outside at night-limiting their participation in urban society beyond structural exclusion and marginalization (Doran \& Burgess, 2011; Rader, 2004). Thus, as residents of informal settlements whose lives are greatly affected by violence and crime and, even more so, by the fear of it, women who reside in these communities should be in conversations and research about violence and crime response and prevention in informal settlements. The purpose of this paper, therefore, was to help fill a gap in the violence literature by exploring the causes of and potential prevention or response strategies to violence and crime in informal settlements in Nairobi from the perspectives of women who live there. 


\section{Methods}

\subsection{Study Site}

Data for this study were collected in Mathare Valley Informal Settlement (Mathare) in Nairobi, Kenya in 2016 as part of a study investigating factors associated with women's access to space and services, women's perceptions of safety in their communities, and their strategies to prevent and address these challenges. Mathare is home to around 200,000 residents and is one of the oldest, largest, and most-densely populated informal settlements in Nairobi. While many languages are spoken in Mathare, Swahili, or Shenga derivative of Swahili with lexicon drawn from Swahili, English and various ethnic languages of Kenya - is the lingua franca in Mathare (Mutiga, 2013).

\subsection{Data Collection}

In-depth, semi-structured interviews in the participants' homes followed by go-along interviews in the community were carried out with 55 female residents of Mathare. In a go-along interview, participants take researchers on a walk through spaces and places in their communities that are salient to them while narrating their experience of those spaces and places (Keene, 2018). Go-along interviews allow researchers to witness the 'lived experience' of space and place through simultaneous observation and narrative. A purposive sampling technique was used to recruit women into the study. Local government and representatives from non-profit organizations in Mathare helped recruit women for introductory meetings about the study. Maximum variation sampling was used to select 55 participants from a list of interested women who attended the meetings. Women represented a broad range of demographic characteristics and had varying access to services. We also made sure to sample at least 5 women from each of Mathare's 11 villages. Women in the study were at least 18 years old, residents of Mathare for at least 6 months, able to provide consent, and fluent in Swahili or English. All participants provided written consent to participate. Interviews were carried out by a team of two researchers-one foreign-born, white, and female-identified and one Kenyan-born, Black, and female-identified. Both researchers lived in Nairobi throughout the data collection and early analysis period (2015-2017) and speak both Kiswahili and English. Interviews were audio recorded and transcribed in full.

\subsection{Analysis Strategy}

Transcriptions from in-depth interviews were analyzed using NVivo qualitative analysis software version 12 (QSR International, 1999). A modified grounded theory approach guided data collection and analysis. Researchers' experience and sensitizing concepts 
related to causes of violence and crime and suggestions about how to prevent or respond to them in informal settlements were used to develop a list of predefined codes. Two researchers - one who was the principal investigator on this study and part of the original data collection team and another, a Kenyan research colleague, with local ties to the Mathare community-used this list to carry out cross-case, thematic analysis-adding their own codes and concepts as they reviewed and analyzed the transcripts. All coding was done in the original language of the interview (Swahili or English) by the two researchers who speak both English and Swahili. The two researchers reviewed each other's codes, concepts, and themes related to women's perceptions of the causes of violence and crime in Mathare, their strategies for responding to or preventing them, and barriers to implementing these strategies. Regular discussions between the two researchers took place throughout the coding and review of each other's codes. Discrepancies in the researcher's codes and interpretations of the data were discussed until a consensus was reached according to best practices of qualitative research (Harry et al., 2005).

\section{Results}

\subsection{Participant Characteristics}

Just under half of the women in this study were married and over half of the women in the study identified as the head of their household. A little over a third of the women were employed and over half reported having a business. About $80 \%$ of the participants in this study were between the ages of 25 and 44 years old, with about $15 \%$ above the age of 44 and just $5 \%$ below the age of 25 . Most women in the study had children, with just over half having 1-2 children and about a quarter having 3-4 children. Over half of the participants in this study had monthly incomes less than KSH 10,000 (US\$100).

\subsection{Perceived Causes of Violence and Crime in Informal Settlements}

Women in this study shared their perceptions of what causes, affects, and exacerbates violence and crime in their villages and Mathare as a whole. The most common explanation for violence and crime in Mathare was idle youth, but leadership and government challenges, corruption and/or inadequacy of police, community barriers, tribalism, and lack of protective infrastructure also emerged as contributing factors.

Idle Youth. Many women in this study reported that unemployed or "idle" youth are primarily responsible for acts of crime and delinquency in Mathare. For example, Anna shares, "For me what I think leads to insecurity is unemployment, when they [youth] are idle during the day, in the evening, they will be desperate for food or money. It is a must 
they use whatever means possible to get something." (Anna, 5). Rose further suggests that dropping out of school compounds the issue of unemployment for some youth:

A lot of youth do not have work. Many youth have dropped out of school. If they drop out of school and they are still young, they spend a lot of time in the video shops. If they want to eat, it is a must they enter crime. (Rose, 7)

Most women who spoke about youth and petty crime blamed the situation on lack of employment and opportunity. There were some, however, who expressed frustration towards youth. Christine, for example, felt that youth did not want to work even if given an opportunity,

Our youth don't want to work, they want you to go and look for work. They come and steal from you. Even the government has tried. Nothing happens. The [youth] hide themselves in the alleyways, then when the police leave, they return to the streets (Christine, 6).

Parenting. Although many women seemed to suggest that violence and petty crime in Mathare are a result of individual behaviors of youth, especially boys/men, several women also blamed the parenting of youth for insecurity in the settlement. Several women reported that parents are unwilling to hold their children accountable for criminal or violent behavior; thus, the cycle of crime and violence in Mathare never ceases. Julia, for example, states,

You might find that someone's child is a thief...when they get arrested by police you find his parents are coming to you saying they want to pay you so that you can drop the case. I am sure that this child will never change if something is not done...those people who do that, they just want to talk, pay, and terminate the case, they don't want justice. (Julia, 10)

While Julia suggests that parents being unwilling to hold their children accountable for criminal behavior may contribute to crime and violence, she also suggests that there may be other, systemic issues that may reinforce these issues in Mathare. Poverty, for example, may contribute both directly, as a factor driving theft as a means to survive or meet household responsibilities, and indirectly, through people's acceptance of financial compensation in exchange for their silence rather than justice for crimes and violence committed against them, i.e., "You find that a woman and/or her child has been raped at night during a robbery/theft. Then she is offered 50,000 shillings and then she takes the money to withdraw the case. What happens? Justice is never served." (Julia, 10) 
Masculinity. Some participants seemed to suggest, especially when talking about rape or sexual assault, that crime is not just a product of circumstance, but is an expected or socially accepted pattern of behavior, particularly for men. Catherine, for example, seems to uphold a sort of "boys will be boys" mentality about rape in Mathare. If a girl is "beautiful" and a boy is not married, rape might be inevitable, e.g., "those thieves, maybe, they are not married so if they see that you are beautiful they will steal from you and rape you" (Catherine, 6). Similarly, Esther shares, "we refuse to go because we know we might find people outside who might rape you. You know men; that is their job. That is what stops us from going there at night" (Esther, 2).

Lack of Policing Systems. Many respondents also identified inadequate policing as a cause of violence in Mathare. Some women described a complete absence of police in the community, e.g., "there are no police officers patrolling this place, there is no one who's taking care of us. If you are attacked you can shout out for help, but nobody will come to help you" (Caroline, 8). Others stated that even if the police are deployed to the area, patrolling schedules are inadequate, e.g., "Security is a big problem in this area, because even when the police come, they only patrol for four hours, then they go" (Christine, 6).

Still others suggest that the officers that are deployed to Mathare are not invested in maintaining security in the community, i.e., "issues arise if those who are given the security jobs get too used to this village. They stop doing their jobs. They start going about their own business. They go and get drunk. You see?" (Elizabeth, 11). Finally, a few women described corruption among police officers as a persistent issue exacerbating insecurity in Mathare, e.g.,

You know the police officers they bring here are acquaintances with thieves in this area; so, even if you scream, the thieves will just run away. The police will promise to follow them, but they won't follow them. Sometimes when they arrest them they just set them free. (Rose, 11)

Government Disinvestment. While some women saw crime and violence as a result of individual behavior or a failing of community members, themselves, many stated that residents do not have the power they need to promote safety in the communities. This lack of power seems to exist on multiple levels. Some women see crime and violence in Mathare primarily as failings of the government. Dorcas, for example, blames politics and local leadership for insecurity in Mathare:

It's just the leadership. It's those leaders we have that cause these things because you will get a person that wants to show he is a better leader than the other 
person...If you didn't support him/her then your security will be threatened. (Dorcas, 6)

Several women in the study felt abandoned by the government; yet powerless to tackle security issues without government support, e.g., "security is not good. I don't see how it will improve unless the government starts to care" (Elizabeth, 11). In fact, for some women, like Priscilla, it feels as if the onus of responsibility for ensuring their safety, including financing, has been left entirely up to the residents of Mathare, i.e., "You know security requires money, but there is no day the area counsellor has ever offered to pay for security. Like here in Mathare, no one has ever offered to pay for police so we can have security here." (Priscilla, 8)

Lack of Resources/Power for Community-led Security. In an environment in which formal systems of maintaining security do not exist, the responsibility for security falls to communities. For example, Nyumba Kumi, Swahili for "ten houses," is a governmentinitiated community-watch program that has been promoted in informal settlements all over Nairobi, including Mathare. The initiative encourages groups of citizens from the same area, e.g., 10 neighboring households, to meet regularly and to get to know their areas and neighbors so that they are better able to identify suspicious or unusual behaviors and report them to their fellow community members and the police. However, while the Numba Kumi is a government-led initiative, the government does not provide resources or support for the program. According to some respondents, without government support and adequate resources, these community-led security initiatives lack the authority, power, and resources to be effective against criminals and perpetrators. Shai, for example, describes why the community security group in her area may be unable to confront criminals or perpetrators:

[The criminals] came the day before yesterday. They took whatever they wanted [from a supermarket] and also a chemist around the corner there...They are armed. So, because they are armed...they don't feel like we [the security people] should interrupt them. The criminals see [our security] are coming; they just go ahead because they are armed and the security that we have they've got machetes. You cannot compare attacking somebody with a machete and the other person has got a gun. (Shai, 9).

Mistrust in Community-led Security. Women in this study also expressed mistrust or disappointment in community-led security initiatives. Julia, for example, mistrusts community-led security because leaders of the initiatives and in the community, more broadly, do not hold themselves and their families accountable for their own contributions to violence and crime: 
The main issue we have is community, they don't want to take action. Right now, the what, the Nyumba Kumi [ 10 houses] initiative has been adopted. You will find that those people who are in the Nyumba Kumi, their children are the thugs/criminals; so, they can't report them. And then, if I know the child of someone is a thug/criminal and I go and report them, I will be isolated. So, it's a must I keep quiet. And then, you will find those people who have a say in the village, those who have been selected to be the leaders of the village, those who were chosen, I don't know, by the chief, those who are doing the community policing...They don't want to say their children are the thugs/criminals; so, this thing [insecurity], there is no day when it will end. It will only be changing, going around in circles. It will just continue. (Julia, 10)

Some women were willing to pay for community-led security initiatives, but they, too, have lost trust in these initiatives. Some women, like Cecilia, for example, not only distrust these community-led security initiatives to protect them, but believe those who are tasked with maintaining safety might, themselves, become the perpetrators of crime and violence:

There was a time when you would go outside and you would be robbed. Now there are security people. They come to your house and ask for money for providing security. But at the moment, you will hear, like last night, there is a supermarket here. It was broken into and robbed. We say we have security, but around here, it's like we never really have security. We can even say, it could be them [the guys we pay to provide security] that are robbing us. (Cecilia, 9).

Other respondents suggest that community members who have taken on or been given the responsibility to respond to and prevent crime and violence in their areas may, also, in an effort to protect their communities, accidently perpetrate violence against innocent people. Millicent, for example, describes an incident in which her neighbor was mistaken for a thief and beaten up on the way to use a toilet at night-adding to the atmosphere of fear, insecurity, and mistrust in the community:

There was a time we had a case, of just a neighbor, he had a stomach problem; so, he wanted to go [to the toilet], but the people there don't know him, so you know at night, when you come out you find a man, you just know he's a thief, so he was beaten. Before people realized that he was a neighbor, he had already been beaten; so, it's also not safe for a man (Millicent, 1).

Lack of Protective Infrastructure. In addition to potential behavioral or social causes of insecurity in Mathare, women identified lack of protective infrastructure as a catalyst for 
violence and crime. For example, several women suggested that lack of lights in the toilets allows perpetrators to hide in the darkness of the toilets and attack women, e.g., "about two weeks ago I heard that there was a child who was raped in the toilet...you get in and you don't have a light, it is very easy to get raped while you are in there" (Annabelle, 2). In addition to inadequate or non-existent lighting in toilets, some women identified a lack of security lights around the neighborhood as a potential challenge to maintaining security. For example:

The plot is very dark because there are no security lights outside, and during the night, when people are asleep, they put off their lights; so, it's usually dark and you don't feel safe going at the back there due to our security, you know. There might have been somebody just seated in the darkness. He will grab you; so you feel like...I cannot go to the back during the night" (Shai, 9)

Several women also identified gates as a tool for maintaining security, for example "Outside the security is bad. Thieves are many. They stab people with knives. Now, you cannot go outside at night. You don't know who is outside at night. But we have a gate there" (Florence, 4) or "Back then security was good, that's when I had just moved here [to this plot]...Women were safe you know. No one else could pass through that upper gate and the lower gate remained closed" (Millicent, 8). A lack of gates, on the other hand, was seen as a barrier to maintaining security in homes, buildings, and housing plots.

Tribalism/Ethnicism. Finally, several women identified tribalism, or ethnic prejudice, as a cause of violence in the time leading up to presidential elections. Some women have been personally attacked because of their tribal affiliation, e.g., "Down there, in 3C...I got attacked because of my tribe.... In no.10, here, only during elections is when we get worried" (Helen, 3). Several women, in fact, stated that they had to relocate to new villages because of conflict or fights that broke out between different tribes, even if they, themselves, were not directly attacked or involved in the fight, e.g., "The place where I used to be was burned down. We used to live in Bonde. Now when the war broke out ... between the Luos and the Kikuyus...they got into chaos...it was a machete fight. They burned down the houses, and we fled here" (Maxine, 2).

Regardless of whether or not a woman had actually experienced a personal attack related to her tribal affiliation, many women feared such an attack. Jane, for example, was deeply fearful that she would be attacked because of her tribal affiliation during the time leading up to the presidential elections:

You know the Luhyas, we are always hated, they are always hating us, and even beating us. They even say, now that the election has started, they must attack us. 
That's what they say. Even now we are afraid. I don't know where we are going to go..." (Jane, 10).

\subsection{Strategies for Responding to and Preventing Violence and Crime}

Despite facing many economic, environmental, and day-to-day challenges, for many women in Mathare, violence and crime are the biggest issues; thus, developing effective response and prevention strategies in this settlement is paramount. In the words of Nancy, "if there was security, everyone would be okay" (Nancy, 7). Women in this study provided a number of suggestions about how to improve security in Mathare. Most of these strategies clearly target each of the causes of crime and violence women also identified in the study, but, for some women, the response and prevention strategies, without proper supports, can also become causes of crime and violence-creating a cycle of mistrust and corruption that has been difficult to break in these settlements. Many women have recommendations for strategies to respond to and prevent crime and violence in their villages and communities, but some have lost hope or trust in community or police interventions-turning, instead, to God for protection.

Youth Employment. For many women in the study, employing youth is the most important strategy to reducing crime and violence in Mathare. Many believe that youth are the primary perpetrators of crime and violence in Mathare. Thus, many also believe that if youth were employed, they would no longer commit crimes, e.g., "security would be better if youth were employed. If youth have jobs to do, they can't steal or rape people" (Catherine, 6). Some women cited that youth employment would be a successful strategy to prevent theft because youth would be making money and, therefore, would have no reason to steal anymore. Others felt that employment would simply limit the time they had to commit crime or perpetrate violence against women. For example, "NYS [the National Youth Service] helped because, you see, the youth, who were the ones stealing from people, were given work; so, they didn't have time to go and steal. When they were working...they go, they come back, they eat, and they sleep" (Dorcas, 6). Some women even suggested that youth, themselves, should be engaged in securing Mathare, e.g., "If youth were given the charge of protecting people here, it would be good" (Pauline, 8).

Many women in this study described, in particular, how the employment of youth through the NYS Slum Improvement Initiative (SII) helped reduce crime and violence, particularly rape in Mathare. For example, "NYS comes and gives jobs to the youth, then it [insecurity] reduces a bit" (Candice, 1) or "the people who used to rape, they are young people because they are using drugs and everything; so, they are idle. So, the NYS thing captures the youths. They train them as they go do those services. So now, the insecurity has come down." (Esther, 2). Some women, on the other hand, lost trust in the NYS SII 
because corruption in the larger NYS organization resulted in a number of interruptions in and the eventual cessation of the SII. These women feel that youth need more permanent or sustainable opportunities, e.g.,

For me, I would say if the idle youth can be given jobs that are sustainable not like the NYS one that was cut short without notice and a plan. That's the main thing that I am advocating for and that the youth should also be empowered. If they can find an organization that can keep them busy. Someone can put up an industry and employ them. It will also be important for us to foster talent. If there are those that can sing, then they should be encouraged to sing. Those that are gifted in making crafts, should be encouraged to do that. Those who have no idea what they want to do, they should also be involved and be taught sustainable ways of creating employment and other long-term activities. (Mwa, 11)

Youth Education. In addition to employment, women felt that youth education is a critical strategy for preventing violence and crime in Mathare. Anna, for example, states, "I would say that they [youth] should be taken back to school and others should look for work" (Anna, 5). Some women believe they, too, have a responsibility to work and to help youth to study, e.g.,

Even for women, working is a must...Like me, if I get money, I educate my child. If they study well, they won't do those bad things. They will have something. They will be thinking. They will be going to school. They won't be sitting around like someone who doesn't study (Jennifer, 7).

Policing. While most respondents proposed increased efforts to employ and educate youth, many also identified the need for a stronger police presence in their settlement communities, e.g., "when there are more police, security is safe" (Catherine, 6) or "I don't see how this place will be secure unless you put policemen on every street, a policeman in every alleyway" (Elizabeth, 11). Respondents also suggested the addition of security guards to monitor housing plots or buildings. For example,

You see, like in our plot, there are always people using this route. There are two gates to go out this way and to go that way. Now, people are just passing, even at night. They don't close the gates. But if there was security, he could prevent this thing. (Pricilla, 8)

While some women, like Dorcas, called for the deployment of a few additional policemen to patrol the area, e.g., 
If we had security or if they would deploy policemen for us, say if they deployed 5 or 3 or 2 policemen, then we won't fear going out. Because when they are there, there won't be people [criminals] walking around... (Dorcas, 6 )

Other respondents, indicated, that a stronger police presence is a function of government or local leadership involvement and resources. For example, "I suggest that they build a police station near here. Then, at least, it would be safe." (Sham, 8). The use of the term "they" implies that someone with authority and resources should be responsible for providing police and security in Mathare, which was connected to respondents call for more government leadership and investment in informal settlements.

Government Leadership and Investment. Several women emphasized the need for government and local leadership to be involved in initiatives to improve safety and reduce violence and crime. Susan suggests, for example, that the safety and protection of citizens is an integral part of the government's job, e.g., "maybe those leaders, let's say the chiefs and DOs (district officers), realized there is no security in the places that they are supposed to protect, shouldn't they get fired?" (Susan, 5).

Protective Infrastructure. A few women in the study also suggested small measures that could be taken to help women feel safer in informal settlements. The suggestions included adding gates to protect housing plots; adding security guards at those gates; putting lights in toilets, alleyways, or buildings women may need to pass through at night, and adding security lights around the neighborhood. For example, "there are those things that, if we put them in place, they will make people feel safe...Like putting security lights in place so that if a person is walking there, you can see them. Things like that" (Pricilla, 8). Carol also described how the simple addition of a make-shift gate that prevented people from using the alleyway next to her house, created a sense of safety for her, and how the destruction of the gate marked a reversal of that sense of safetysuggesting there may be a need for consistency in infrastructural investments in the community, e.g., "I can say that, with that gate, we had security...But now, there is none...People came and demolished it [the gate] completely" (Carol, 7)

Some respondents identified bigger modifications in the built or physical environment as helpful tools to reduce crime and violence and the overall atmosphere of insecurity in informal settlements. Faith, for example, described how the construction of a new row of houses cutoff a common pathway for criminals to move easily between houses and the river, e.g., "I know someone who has been raped...the girl who lives just down there...but now it's better. Before they built these houses back here, they could come and take a girl and carry her on their back [to the river]" (Faith, 1). 
Community-based Security. There were women in this study who also believe that prevention is the responsibility of the residents, themselves, e.g., "you know security starts with each person, even me." (Cecilia, 9). Eli, for example, believes crime and violence can be managed well by knowing and communicating with neighbors:

Here, our village is not so bad...You and your neighbors know each other. So, you are my security, I am your security, like that. And, also, you see those phones? Phones are making a difference. If you feel uncomfortable, you alert your neighbor, "eh, I hear movements outside. I hear some noise at your house." Now, I am alerted...The phone has made a difference." (Elizabeth, 11)

Some women support community-based security, e.g. Nyumba Kumi, that relies on residents knowing their neighbors and checking in with each other or reporting suspicious behavior, e.g. "I can say that the Nyumba Kumi initiative has helped people to be familiar with their neighbors" (Mwa, 11). Others suggest that prevention and response require a more direct approach. Patricia, for instance, provided an example of how community-led security had been successful in reducing crime in her village:

Security is not bad here. It's good...It is safe around here, but I say that it is safe because a while back it was bad...a long while ago, there were violent thieves. They were coming, breaking into houses, stealing things. Then, when they were staying down there [by the river], the villagers and the elders of the village decided to try to force them [the thieves] to move. They moved and now it's been two years. (Patricia, 11)

Community Punishment or Mob Justice. In an environment where crime and violence are high, there are inadequate resources, minimal government engagement, and limited mechanisms for preventing and managing crime, some communities adopt their own systems of punishment and justice. While women did not advocate directly for this form of prevention, several of them pointed out that these systems had been effective at reducing crime in their villages. For example, "the main cause of change has been the residents' initiative of killing those thieves every time they catch them." (Mwa, 11). Yet, these punitive or mob justice measures, while effective in some instances, also seemed to have a finite effect on crime and violence. For example,

Security gets better in this place when one thief is killed. If one thief is caught, beaten, and killed, [the others] will stop for two months...You can even walk at 11 at night...If a thief is killed, I will walk even at $1 \mathrm{am}$. There are no thieves to fear. But, after those two months, a few thieves will return again (Julia, 10). 
Community Reconciliation. Participants identified the months leading up to presidential elections as a prolonged period of insecurity and violence as a result of political incitement of tribalism/ethnicism. However, they also described a community reconciliation, a rebuilding of trust among residents, and a return to reduced levels of violence post-election, e.g.,

Now, during the elections people don't get along due to the different political parties, but at another point in time, when the elections have finished, you will see people reconcile and the security will be good, if I held a grudge against her we would return to being friends once more. (Dorcas, 6)

Some women even suggested that the end of the elections marks a time when residents of the settlement reinvest in community-led security initiatives, e.g., "Since the elections ended, security has been better. It's us, the community members who do the policing ourselves. We hold meetings. If you hear something, you alert your neighbors. We as community members are one, don't you see?" (Eleanor, 11).

Devine Intervention. For some women, God is the only protector in the settlement. Caroline, for example, describes how God provides a sense of safety and protection for women who feel completely abandoned or alone in an environment that is insecure and unsafe:

It is God who protect us. Without God, in these houses, you can't even sleep. You know, if you sleep in a place like this, you hear people walking outside your house at night. Time just keeps running. Then you hear a person has opened the gate. A person has entered the house. When you get up you realize that you are okay. You thank God for protecting you...God is our security, there is no other security (Caroline, 7).

\section{Discussion}

The purpose of this paper was to explore women's perceptions of drivers of crime and violence, barriers to preventing crime and violence, and their suggestions to improve safety in informal settlements, particularly Mathare. Findings suggest that women's strategies for prevention and management track very closely with their perceptions of the causes of violence and crime-with many drivers being matched by a potential prevention or response strategy. However, many women also highlighted several barriers to implementing these strategies. In some instances, efforts to prevent or respond to crime and violence could devolve into a mechanism that exacerbates these issues-a cycle that is seemingly propelled by systems of government disinvestment and 
marginalization of these communities. Community engagement is essential to the planning, implementation, and sustainability of interventions to improve life in informal settlements (Lilford et al., 2017); thus, heeding women's suggestions and warnings is critical not only to developing a more complete understanding of crime and violence in these communities, but also in determining strategies to respond to and prevent these issues.

There are many theories that have been developed to explain crime and violence causation in the Global North and a few of these theories, e.g., general crime theory, situational, social disorganization, modernization, underdevelopment, and routine activities theories have been applied or discussed in SSA contexts to explore crime and violence causation (see for example, Arthur \& Marenin, 1995; G. D. Breetzke, 2010; Breetzke \& Horn, 2008; Burt et al., 2006; Marenin \& Reisig, 1995). The general consensus among scholars, however, is that these theories are invalid or insufficient in and across SSA contexts. Thus, rather than seeking to test or apply a specific theory of crime in a large informal settlement in Nairobi, we sought to explore women's perceptions of causes of crime and violence within their communities and their strategies for addressing these issues. While some of the causes of crime and violence women discussed in this study might align with one or more criminological theories, e.g., strain, labelling, routine activities, modernization, or underdevelopment theory, no single theory seemed adequate, particularly with regard to recognition of the role legacies of colonialism and government disinvestment play in crime and violence in informal settlements in Nairobi (Stavrou, 2002). Studies employing criminological or sociological theories of crime should do so with a critical lens that takes into account the history and legacy of colonialism/white supremacy in informal settlements.

Residents in informal settlements in Nairobi have always been marginalized, disenfranchised, and excluded. These settlements were first formed during British colonial rule by native Kenyans who were considered illegal residents of the city by the colonial government and, therefore, denied access to public housing and formal services (Wanjiru \& Matsubara, 2017). While Kenya received its independence from British colonial rule in 1963, residents of informal settlements are still disenfranchised-largely excluded from formal services like water, sanitation, and electricity; land tenure security; social programs, access to public health services; and dependable security and policing programs (Corburn et al., 2012). Government investment in education and employment programs in informal settlements has been limited or inconsistent, and residents of informal settlements still face threats of forced eviction and/or demolition of houses and personal property (Corburn et al., 2012; Oduro et al., 2012; Wanjiru \& Matsubara, 2017). Research suggests that in the absence of government services, many residents rely on gangs for service provision and security, which also comes at cost (Mutahi, 2011). It is 
within this history and context that residents of informal settlements have learned to cope, survive, and manage their daily tasks in spite of poverty, lack of employment and educational opportunities, and marginalization and exclusion.

Women in this study identified a number of potential drivers of crime and violence and barriers to creating or maintaining security in Mathare, which included individual or behavioral factors like poor work ethic of youth; familial or household-level drivers such as lack of accountability on behalf of parents with children who are involved in crime and violence; community-level challenges like mistrust in neighborhood security initiatives; environmental or infrastructural issues like a lack of security lighting and security gates; and social factors like normalization of male perpetration of sexual violence against women. Additionally, women highlighted systemic and institutional drivers like widespread unemployment, particularly of youth; ethnic prejudice or tribalism incited by politicians during election periods; poverty; inadequate policing; and lack of government engagement in tackling security issues. While women identified drivers of violence and crime at multiple levels of the community ecology, these individual-, household-, community-, and environmental drivers were entrenched in systemic issues like government disinvestment in these communities and marginalization, segregation, and exclusion of settlement residents.

A majority of women in this study, for example, associated "idle youth," particularly young boys, with crime and violence in informal settlements, especially theft and rape. Yet, in describing youths' involvement in crime and violence, many women, though not all, seemed to suggest that youth may have few alternatives to crime, particularly theft, i.e., "If they want to eat, it is a must they enter crime." This seems to point to more systemic issues of widespread unemployment and/or exclusion from sustainable employment and educational opportunities, and mirrors results from other studies that have explored urban violence in informal settlements in Kenya, Ghana, Mozambique, and South Africa through young men's narratives and perspectives (Gibbs et al., 2014; Izugbara et al., 2014; Izugbara \& Egesa, 2019; Mariano et al., 2018). Findings from these studies, which seem to align with concepts of strain and feminist theories of crime causation, suggest that crime and violence in informal settlements may, at least in part, be a result of men trying to act like "real men" in a setting where, due to systemic lack of opportunities for employment or success, they are failing to fulfill traditional masculine roles such as earning an income and providing for and protecting their families and communities (Izugbara et al., 2014; Izugbara \& Egesa, 2019; Mariano et al., 2018). In the face of limited opportunities for employment or education most young men in informal settlements spend time idling in the streets (Gibbs et al., 2014); 'hustling,' i.e., pursuing economic strategies that include selling small items on the side of the road; "parking" at a "job corner" waiting for someone to hire them for menial work; or engaging in petty 
crime (Gibbs et al., 2014; Izugbara \& Egesa, 2019). Young men may turn to crime and violence in order to try to fulfill the role of breadwinning and providing for their families (Izugbara \& Egesa, 2019).

Studies also suggest that violence, including sexual violence or rape, might also be an attempt by men to validate their masculinity in a context where fulfilling traditional masculine roles is largely unachievable due to exclusion from or lack of opportunities such as sustainable employment and education, and, consequently, feelings of personal failure, shame and frustration (Izugbara \& Egesa, 2019; Mariano et al., 2018). While several women in this study did not specifically discuss the need to and/or the failure of men to fulfill traditional masculine roles as drivers of crime or violence, a few women did suggest that rape, in particular, was a probable male behavior-suggesting that social norms or expectations around gender may contribute to both men's and women's perception of why and by whom violence and crimes are committed in informal settlements. In many cultures, traditional gender norms and associated sexual roles are upheld, thereby contributing to rape myth acceptance (Durán et al., 2011; Kojo Oduro et al., 2020; Tavrow et al., 2013). Rape myths justify the occurrence of sexual violence by either blaming the victim or absolving the perpetrator (e.g., by saying that men just cannot control themselves; Tavrow et al., 2013).

Although most participants did not discuss the role of masculinity in crime and violence-deviating from findings from previous research focused on male perspectives of crime and violence in informal settlements (e.g., Izugbara \& Egesa, 2019; Mariano et al., 2018) - it is hard to know whether that is because they felt it did not play a role in crime and violence or they did not feel comfortable discussing it. In the context of informal settlements, for example, the constructed gender order and the power of men in the community may have inhibited some women from discussing the role of masculinity in their community and homes (Jewkes \& Morrell, 2012). Female agency can also be temporary, unstable, and context specific. As a result, participants may have felt like they did not have the option to challenge dominant gender expectations in their community (Campbell \& Mannell, 2016; Willan et al., 2020). Future studies would benefit from exploring this further.

Given that the majority of women identified idle youth as the primary source of violence and crime in informal settlements, it is unsurprising that women also suggested that youth employment would be the most effective solution to reduce or prevent crime and violence. Specifically, many women talked about the effectiveness of government-funded programs such as the NYS SII program to reduce crime in settlements. The NYS SII program was launched in 2014 under the Ministry of Devolution and Planning. NYS provided youth with employment opportunities, micro-business loans and savings 
programs, road construction, and sanitation improvement projects (e.g., garbage collection, drainage clean-up, and construction of toilets and sewage systems) (Mitra et al., 2017). Importantly, according to women in this study, NYS also increased safety in informal settlements. Several women in this study, however, also described a loss of trust in the NYS initiative when significant corruption allegations emerged in 2015 causing NYS activities to cease and crime and violence to go back up in informal settlements (Mitra et al., 2017). While this government-led initiative was seemingly successful at deterring crime and violence in informal settlements in Kenya, the corruption and disintegration of the program exacerbated women's already high levels of mistrust in government-led initiatives in these settlements. Thus, while programs like NYS would likely be successful again, long-term, uninterrupted investment and systems of accountability within the program seem critical to the sustainability of government-led initiatives and to rebuild residents' trust of these initiatives in settlements where residents have, historically, been marginalized or excluded by the government since before independence (Fox, 2014).

Pulling from concepts of labelling theory, changing the perception of young men as perpetrators and criminals in informal settlements may also be important for reducing violence and crime in these settlements. Youth residents of informal settlements are often characterized as perpetrators and criminals by outsiders (Izugbara \& Egesa, 2019). Findings from this study suggest that women from within the settlements may also perpetuate this narrative. Unfortunately, this narrative has serious implications for youth. While youth may often be responsible for petty crime such as theft and burglary in informal settlements, young men may not be responsible for most of the violent crimes in these settlements. Findings from a 2011 study suggest that the proportion of homiciderelated injuries in informal settlements in Nairobi was high ( $47 \%$ of all injuries), but findings also indicate that firearm injuries, most of which occur during firing exchanges between armed criminals and the police, were the most common cause of intentional injuries (44\%) followed by blunt force trauma and cuts and stabs (12\%), most of which are sustained during "mob justice" attacks (33\%) (Ziraba et al., 2011). It seems that police, gangs, and community-based security, particularly "mob justice," may actually be the cause of many violent assaults and homicides, and that young men are often the target of these attacks (Izugbara \& Egesa, 2019; Mariano et al., 2018). According to recent research carried out in Kenya, for example, the characterization of young men in informal settlements as criminals has led to police raids; arrests and detention; and youth being beaten, tortured, or shot (Izugbara \& Egesa, 2019) or suspected youth being beaten or burned to death by community enforcers or vigilantes (Mariano et al., 2018).

Women's perspectives from this study seem to both corroborate and contradict these previous findings. A number of women in this study, for example, described the police 
as unreliable, untrustworthy, and/or corrupt-contributing to an overall sense of injustice and insecurity in the settlement-but they did not highlight police raids or brutality as contributing factors to the violence in Mathare. Perhaps this is because young men might be more likely to have negative, unlawful, and violent encounters with police than women (Izugbara \& Egesa, 2019). Additionally, women in this study did not highlight gangs as a primary source of violence, or crime, but, again, the absence of this narrative may suggest that women's direct experiences with gangs are less frequent or less violent. While women in this study did not talk about gangs, police raids, or police brutality against youth, they did suggest that, in the absence of a consistent and reliable police presence, community-led security efforts were sometimes used to control and prevent violence and crime. According to study participants, these extra-judicial, communityinitiated efforts, i.e., "mob justice," led to the killing of suspected thieves and rapists and, in some unfortunate cases, innocent youth. Women did not label these initiatives as crimes or sources of violence. Instead, women who talked about them seemed to perceive them as extreme, but sometimes effective, short-term prevention measures. Women may perceive mob justice as an effective strategy for reducing crime and violence, rather than an act of violence, because they are less likely to be the targets of those initiatives, but for the victims of those attacks, particularly youth in informal settlements, they are acts of violence or homicide.

A number of women in this study advocated for more police stations, police, security guards and community-led security initiatives to reduce and prevent violence and crime in Mathare; however, many of the women were also skeptical of the effectiveness of both police and community-led security. Women in this study seemed to suggest that police were often unreliable and/or corrupt-wasting time or protecting criminals and perpetrators rather than the residents who look to them for security and justice. This finding is corroborated in existent literature that suggests lack of urban planning and governance has led to a sense of lawlessness and structural violence in informal settlements wherein police authorities are unable or unwilling to enter the communities (Oduro et al., 2012) or violent and corrupt when they do (Izugbara \& Egesa, 2019; Stavrou, 2002). In settlements where the government has failed to provide an adequate justice system, community policing initiatives have been introduced to counter the lack of formal and just law enforcement (Mariano et al., 2018; Ziraba et al., 2011). Women in this study cited community-led security initiatives as a potential mechanism to help reduce violence and crime in Mathare; however, several women also suggested that these initiatives were often dishonest or lacked the power to be successful. While community engagement and initiatives are essential to efforts to improve the health and safety of informal settlements (Lilford et al., 2017), the findings from this study suggest that community-led prevention and response initiatives, in particular, may need government investment and/or backing from law enforcement to ensure they have the capability, 
necessary equipment, and authority to safely patrol, report, and/or manage violence and crime in these settlements. In addition, there needs to be oversight or a system of accountability so that residents of the community feel comfortable reporting misconduct and corruption and, relatedly, be able to trust that the representatives in the group are being held accountable for theirs and their children's' contributions to violence and crime and prioritizing residents' lives and safety.

According to several studies focused on youth in informal settlements, men, like many women in this study, recognize that violence and crime in informal settlements is largely a product of systemic exclusion, which often manifests in lack of educational and employment opportunities, economic inequalities, marginalization and discrimination, and government disinvestment and neglect (de Boer et al., 2018; Gibbs et al., 2014; Izugbara et al., 2014; Izugbara \& Egesa, 2019; Oduro et al., 2012; Salahub et al., 2018). Women in this study suggested, for example, that poverty may be directly and indirectly associated with violence and crime in informal settlements. Poverty and lack of opportunities for education and employment drive youth to drop out of school and, in some cases, resort to stealing for survival or to manage household and familial responsibilities. Findings from this study also suggest that lack of economic resources, in combination, with weak policing and justice systems, may also be a barrier to reporting violence and crime and seeking justice in informal settlements particularly for parents of youth-encouraging corruption and a cycle of violence without accountability. Women, out of desperation, fear, and/or distrust in police and legal responses, for example, may accept cash bribes not to report a rape. It seems fairly evident from findings in this study and from previous studies focused on violence in informal settlements that the history of marginalization and exclusion of residents and government mistreatment of and disinvestment in these communities creates or exacerbates many of the drivers of violence and crime (Izugbara et al., 2014; Izugbara \& Egesa, 2019; Oduro et al., 2012; Salahub et al., 2018). Although findings from this study only represent women's voices from one informal settlement in Nairobi, the results corroborate studies that suggest failures in planning and governance, combined with a critical underinvestment in informal settlements has led to violence in informal settlements on a number of levels (Oduro et al., 2012; Salahub et al., 2018). Government disinvestment has led not only to systemic issues of poverty and lack of educational and employment opportunities in informal settlements, but also to inadequate infrastructure and safety features, e.g., housing, land tenure, basic services, security lights and gates (Oduro et al., 2012) - factors women in this study also identify as contributors to crime and violence.

In addition to government disinvestment, political instrumentalization of ethnicity, or political tribalism (Mati, 2019), is another cause of crime and violence women cited in this study. Instrumentalization of tribalism has been used as a tool by politicians in Kenya 
since Britain's colonial rule, and this ethnic-based political mobilization has resulted in inter-ethnic violence every presidential election since 1992 (Mati, 2019). Women in this study highlighted the violent implications political incitement of tribalism has had on their lived experience in informal settlements in the months leading up to a presidential election. Importantly, women also described a community reconciliation that occurs after the presidential elections are over and the political instrumentalization of tribalism ceases. The women described this as a time of forgiveness and rebuilding of trust in each other and in the community - a symbol of incredible resilience and capacity for healing within these settlements. But this political instrumentalization of tribalism and the resulting violence in these informal settlements adds to the distrust in government in these communities.

From supporting community-led security initiatives and consistent law enforcement to investing in strategies to prevent violence and crime altogether e.g., improving infrastructure (security lights) and creating youth education and employment programs, government investment is essential to effective and sustainable reduction of crime in these communities. Government investment is not only important because these sorts of programs are costly, but because the government needs to begin the process of building or rebuilding trust with residents of informal settlements. Since the colonial period, residents of informal settlements have been marginalized, stigmatized, and excluded from formal services and government investment (Fox, 2014; Wanjiru \& Matsubara, 2017). Politicians and government representatives have profited immensely from underdevelopment of informal settlements through land grabbing, rent-seeking, and exploiting marginalized communities for political support (Fox, 2014). The persistent exploitation of and disinvestment in communities has fostered distrust among residents in informal settlements to the point where some women believe that only God can protect them and help them feel safe in their communities; however, this could change. Government trust could be regained and co-production strategies between formal and informal sectors of the community could be developed. The success of the NYS SII program in 2015, for example, illustrated how government-supported initiatives can be effective at reducing violence and fostering positive health, well-being, and development in informal settlements. There is, however, a serious need for trust-building, systems of accountability, and long-term investment to foster truly sustainable and effective change.

Limitations. While this study may provide important research into women's perceptions of drivers of crime and violence and suggestions to improve safety in informal settlements, particularly Mathare, it is not without limitations. First, interviews were conducted by a team of two women - one, foreign-born and white and the other, Kenyanborn and Black. While both researchers lived in Nairobi before, during, and after data collection for this study (2015-2017) and could speak both Swahili and English, both were 
outsiders to the community. The white researcher was visibly a foreigner not only to the settlement, but to Kenya. There are a number of implications the positionality of the researchers and participants may have had on the collection and interpretation of data. For example, although participants stated they were comfortable talking openly about sensitive topics, many may not have been comfortable sharing openly about crime, violence, and government disinvestment with outsiders to the community, including a foreigner. Additionally, data for this study were collected during 2016-a little more than one year prior to the scheduled Kenyan presidential elections when political incitement of tribal/ethnic conflict was a serious concern for women (Shilaho, 2018); thus, some women openly expressed that they did not feel comfortable discussing their own tribal identity or tribalism in the settlement, in general. On the other hand, some women expressed they were more comfortable sharing with outsiders than with someone from within the community who could disclose to others. Having a white female researcher be part of a go-along interview in the community may have also created challenges and discomfort for participants. Participants may not, for example, have felt comfortable guiding researchers through certain places and spaces or sharing openly about violence and crime while moving through the settlement.

While we were transparent about the purpose of the research, many women also hoped that we, as privileged outsiders to the settlement, and, in the case of one researcher, a white, foreigner from a Global North county, would have access to additional resources and/or be in a position to bring money, intervention, and/or development projects into the community directly following the conclusion of the research project. These dynamics may have influenced responses to questions pertaining to crime and violence and, especially, perceptions of solutions to these challenges in the community. Additionally, although data analysis and interpretation for this study were carried out and discussed as a team and results discussed and verified by an advisory board of female residents in Mathare, interpretation of the data must be considered in light of the positionality of the researchers as outsiders to the daily lived experience of participants in the study. Finally, data were collected cross-sectionally in Mathare informal settlement; thus, findings should not be generalized to all informal settlements or to other points in time.

Author Contributions: Conceptualization, S.C.W.; Methodology, S.C.W. Formal Analysis, S.C.W. and L.M.O.; Resources, S.C.W.; Data Curation, S.C.W.; Writing Original Draft Preparation, S.C.W., L.M.O., N.J.A., and L.J.; Writing - Review \& Editing, S.C.W., N.J.A., L.M.O., and L.J.; Project Administration, S.C.W.; Funding Acquisition, S.C.W.

Funding: The lead author on this study was supported by a PEO Scholar Award and a David L. Boren Fellowship for International Study. 
Institutional Review Board Statement: The study was conducted according to the guidelines of the Declaration of Helsinki, and approved by the Institutional Review Board at Rutgers University (Protocol 15-772M) and by the National Commission for Science, Technology, and Innovation (NACOSTI) in Nairobi, Kenya (Permit No. NACOSTI/P/15/7495/7482).

Informed Consent Statement: Informed consent was obtained from all subjects involved in the study.

Data Availability Statement: The data presented in this study are available on request from the corresponding author. The data are not publicly available due to confidentiality concerns. Audio data recorded interview discussions cannot be shared as permission was only received from participants to videotape sessions for the purposes of aiding the study team with transcription.

Acknowledgments: Special thanks are due Francis Barchi, whose mentorship and support of the PI was invaluable. We would also like to thank Everline Achieng, Christine Adhiambo, Anna Mueni, Shainanzi Kaniza, Julia Njoki Nyambura, Mwanaisha Adhiambo Joel, Nancy Kimeu Wanjiru, Milcah Wambui Gakuru, Janefer Kirango, Clarice Akinyi, and Shamim Anyango for their guidance throughout the research project and their commitment to carrying out ethical data collection. You are a wonderful team.

Conflicts of Interest: The authors declare no conflict of interest.

\section{References}

Agnew, R. (1992). Foundation for a General Strain Theory of Crime and Delinquency. Criminology 30 47-88.

Akers, R. L. (1998). Social Learning and Social Structure. Northeastern University Press. Anwar, N. H., Viqar, S., \& Mustafa, D. (2018). Intersections of gender, mobility, and violence in urban Pakistan. Social theories of urban violence in the Global South: Towards safe and inclusive cities, 15-31.

Arthur, J. A., \& Marenin, O. (1995). Explaining crime in developing countries: The need for a case study approach. Crime, Law and Social Change, 23(3), 191-214.

Berkman, H. (2007). Social exclusion and violence in Latin America and the Caribbean (Working Paper, No. 613, Issue.

Brankovic, J. (2016). Women's contribution to social cohesion and violence prevention through the Community Work Programme. 
Breetzke, G. (2010). A socio-structural analysis of crime in the city of Tshwane, South Africa. South African Journal of Science, 106(11-12), 1-7.

Breetzke, G. D. (2010). Modeling violent crime rates: A test of social disorganization in the city of Tshwane, South Africa. Journal of criminal justice, 38(4), 446-452.

Breetzke, G. D., \& Horn, A. C. (2008). Key requirements in the development of a spatialecological theory of crime in South Africa.

Brunton-Smith, I., Jackson, J., \& Sutherland, A. (2014). Bridging structure and perception: On the neighbourhood ecology of beliefs and worries about violent crime. British Journal of Criminology, 54(4), 503-526.

Bursik, R. J. (1988). Social disorganization and theories of crime and delinquency: Problems and prospects. Criminology, 26(4), 519-552.

Burt, C. H., Simons, R. L., \& Simons, L. G. (2006). A longitudinal test of the effects of parenting and the stability of self-control: negative evidence for the general theory of crime. Criminology, 44(2), 353-396.

Campbell, C., \& Mannell, J. (2016). Conceptualising the agency of highly marginalised women: Intimate partner violence in extreme settings. Global public health, 11(1-2), 1-16.

Corburn, J., Ngau, P., Karanja, I., \& Makau, J. (2012). Mathare Zonal Plan Nairobi, Kenya: Collaborative Plan for Informal Settlement Upgrading.

Darkey, D., \& Kariuki, A. (2013). A study on quality of life in Mathare, Nairobi, Kenya. Journal of human ecology, 41(3), 207-219.

de Boer, J., \& Gottsbacher, M. (2019). A fast-moving and dynamic urban landscape. Caroline Moser, Emeritus Professor, University of Manchester, UK, 1.

de Boer, J., Salahub, J. E., \& Gottsbacher, M. (2018). New perspectives on lasting solutions. Social Theories of Urban Violence in the Global South, 208.

Doran, B. J., \& Burgess, M. B. (2011). Putting fear of crime on the map: Investigating perceptions of crime using geographic information systems. Springer Science \& Business Media.

Durán, M., Moya, M., \& Megías, J. L. (2011). It's his right, it's her duty: Benevolent sexism and the justification of traditional sexual roles. Journal of sex Research, 48(5), 470-478.

Elfversson, E., \& Höglund, K. (2019). Violence in the city that belongs to no one: urban distinctiveness and interconnected insecurities in Nairobi (Kenya). Conflict, Security $\mathcal{E}$ Development, 19(4), 347-370.

Felson, M. (1998). Crime and Everyday Life. Pine Forge Press.

Fox, S. (2014). The political economy of slums: Theory and evidence from Sub-Saharan Africa. World Development, 54, 191-203.

Gibbs, A., Sikweyiya, Y., \& Jewkes, R. (2014). 'Men value their dignity': securing respect and identity construction in urban informal settlements in South Africa. Global health action, 7(1), 23676. 
Gottfredson, M., \& Hirschi, T. (1990). A General Theory of Crime. Stanford University Press.

Harry, B., Sturges, K., \& Klingner, J. (2005). Qualitative data analysis: Mapping the process. Educational Researcher, 34(2), 3-13.

Herbert, D. (2002). Crime and its Control in Urban Environments. In W. K. D. Davies \& I. J. Townshend (Eds.), Monitoring Cities: International Perspectives (pp. 541-555). International

Geographical Union, Commission on Monitoring Cities of Tomorrow. Hirschi, T. (1969). Causes of Delinquency. University of California Press. Izugbara, C., Tikkanen, R., \& Barron, K. (2014). Men, masculinity, and community development in Kenyan slums. Community Development, 45(1), 32-44.

Izugbara, C. O., \& Egesa, C. P. (2019). Young men, poverty and aspirational masculinities in contemporary Nairobi, Kenya. Gender, Place \& Culture, 1-21.

Jewkes, R., \& Morrell, R. (2012). Sexuality and the limits of agency among South African teenage women: Theorising femininities and their connections to HIV risk practises. Social science \& medicine, 74(11), 1729-1737.

Keene, D. E. (2018). Qualitative Methods and Neighborhood Health Research. In D. T. Duncan \& I. Kawachi (Eds.), Neighborhoods Heal (2nd ed., pp. 193-218). Oxford University Press.

Kojo Oduro, J., Seidu, A.-A., Ameyaw, E. K., Sambah, F., Ahinkorah, B. O., Budu, E., Appiah, F., \& Baatiema, L. (2020). Bride price payment and justification of sexual violence among women in Ghana. Journal of interpersonal violence, 0886260520966678.

Krug, E. G., Dahlberg, L. L., Mercy, J. A., Zwi, A. B., \& Lozano, R. L. (2002). World report on violence and health.

Lamb, G. (2019). Social cohesion and violence in South Africa: Constructing a puzzle with missing pieces. Crime, Law and Social Change, 72(4), 365-385.

Langa, M., Masuku, T., \& van der Merwe, H. (2019). Towards safer communities: the impact of the community work programme on the prevention of urban violence in South Africa. In Reducing Urban Violence in the Global South (pp. 90-103). Routledge.

Lilford, R. J., Oyebode, O., Satterthwaite, D., Melendez-Torres, G., Chen, Y.-F., Mberu, B., Watson, S. I., Sartori, J., Ndugwa, R., \& Caiaffa, W. (2017). Improving the health and welfare of people who live in slums. The Lancet, 389(10068), 559-570.

Mahadevia, D., \& Desai, R. (2019). Everyday violence in urban India: Is planning the driver or mitigator? In Reducing Urban Violence in the Global South (pp. 177-199). Routledge.

Marenin, O., \& Reisig, M. D. (1995). "A general theory of crime" and patterns of crime in Nigeria: An exploration of methodological assumptions. Journal of criminal justice, 23(6), 501-518. 
Mariano, E., Slegh, H., \& Roque, S. (2018). Men in the city: Changing gender relations and masculinities in Maputo, Mozambique. In Social Theories of Urban Violence in the Global South (pp. 54-70). Routledge.

Markowitz, F. E., Bellair, P. E., Liska, A. E., \& Liu, J. (2001). Extending social disorganization theory: Modeling the relationships between cohesion, disorder, and fear. Criminology, 39(2), 293-319.

Mati, J. M. (2019). Ethnicity and Politics in Kenya. In R. S. (Ed.), The Palgrave Handbook of Ethnicity. Palgrave Macmillan.

Matsueda, R. L. (1992). Reflected Appraisals, Parental Labeling, and Delinquency: Specifying a Symbolic Interactionist Theory. American journal of sociology, 97 1577-1611.

Mitra, S., Mulligan, J., Schilling, J., Harper, J., Vivekananda, J., \& Krause, L. (2017). Developing risk or resilience? Effects of slum upgrading on the social contract and social cohesion in Kibera, Nairobi. Environment and Urbanization, 29(1), 103122.

Moncada, E. (2013). The politics of urban violence: Challenges for development in the global south. Studies in Comparative International Development, 48(3), 217-239.

Mutahi, P. (2011). Between illegality and legality:(In) security, crime and gangs in Nairobi informal settlements. South African Crime Quarterly, 37, 11-18.

Mutiga, J. (2013). Effects of language spread on a people'phenomenology: The case of Sheng' in Kenya. Journal of Language, Technology \& Entrepreneurship in Africa, 4(1), 1-15.

Oduro, G. Y., Swartz, S., \& Arnot, M. (2012). Gender-based violence: Young women's experiences in the slums and streets of three sub-Saharan African cities. Theory and Research in Education, 10(3), 275-294.

Owusu, A. Y., Oteng-Ababio, M., Owusu, G., Wrigley-Asante, C., \& Agyekum, M. W. (2019). Opening up or closing off: Urbanisation, violent crime, and the "poverty penalty" in Ghana's four largest cities. In Reducing Urban Violence in the Global South (pp. 40-66). Routledge.

Parks, M. J. (2014). Urban poverty traps: Neighbourhoods and violent victimisation and offending in Nairobi, Kenya. Urban Studies, 51(9), 1812-1832.

QSR International. (1999). NVivo Qualitative Data Analysis Software. In (Version 12)

Rader, N. E. (2004). The threat of victimization: A theoretical reconceptualization of fear of crime. Sociological Spectrum, 24(6), 689-704.

Roberts, B., \& Gordon, S. (2016). Pulling us apart? The association between fear of crime and social cohesion in South Africa. South African Crime Quarterly, 55, 49-60.

Salahub, J. E., Gottsbacher, M., \& De Boer, J. (2018). Social theories of urban violence in the global South: towards safe and inclusive cities. Routledge.

Sampson, R. J. (2012). Great American City: Chicago and the Enduring Neighborhood Effect. University of Chicago Press. 
Sampson, R. J., \& Groves, W. B. (1989). Community structure and crime: Testing socialdisorganization theory. American journal of sociology, 94(4), 774-802.

Sampson, R. J., Morenoff, J. D., \& Gannon-Rowley, T. (2002). Assessing "neighborhood effects": Social processes and new directions in research. Annual review of sociology, 28, 443-478.

Shaw, C. R., \& McKay, H. D. (1942). Juvenile delinquency and urban areas. University of Chicago Press.

Shaw, M., \& Carli, V. (2011). Practical approaches to urban crime prevention.

Shilaho, W. K. (2018). Political power and tribalism in Kenya. Springer.

Stavrou, A. (2002). Crime in Nairobi: results of a citywide victim survey. Un-habitat.

Stewart, J., \& Katsande, R. (2018). "We don't know when the trucks will come": The quest for safe and inclusive cities in Zimbabwe. In Social Theories of Urban Violence in the Global South (pp. 71-84). Routledge.

Tavrow, P., Withers, M., Obbuyi, A., Omollo, V., \& Wu, E. (2013). Rape myth attitudes in rural Kenya: toward the development of a culturally relevant attitude scale and "blame index". Journal of interpersonal violence, 28(10), 2156-2178.

Taylor, R. B., \& Covington, J. (1993). Community structural change and fear of crime. Social problems, 40(3), 374-397.

Villarreal, A., \& Silva, B. F. (2006). Social cohesion, criminal victimization and perceived risk of crime in Brazilian neighborhoods. Social Forces, 84(3), 1725-1753.

Wanjiru, M. W., \& Matsubara, K. (2017). Slum Toponymy in Nairobi, Kenya. Urban and Regional Planning Review, 4, 21-44.

Ward, C., van der Merwe, A., \& Dawes, A. (2013). Youth violence: Sources and solutions in South Africa.

Willan, S., Gibbs, A., Shai, N., Ntini, N., Petersen, I., \& Jewkes, R. (2020). Did young women in South African informal settlements display increased agency after participating in the Stepping Stones and Creating Futures intervention? A qualitative evaluation. Social science $\mathcal{E}$ medicine, 265, 113302.

Williams, R. J., \& Castellanos, P. (2020). Youth perceptions of violence in Western Honduras. Third World Quarterly, 41(3), 397-414.

Woldoff, R. A. (2006). Emphasizing fear of crime in models of neighborhood social disorganization. Crime Prevention and Community Safety, 8(4), 228-247.

Ziraba, A. K., Kyobutungi, C., \& Zulu, E. M. (2011). Fatal injuries in the slums of Nairobi and their risk factors: results from a matched case-control study. Journal of Urban Health, 88(2), 256-265. 